\title{
Heterometal nanoparticles from Ru-based molecular clusters covalently anchored onto functionalized carbon nanotubes and nanofibers
}

\author{
Deborah Vidick $^{1}$, Xiaoxing Ke ${ }^{2}$, Michel Devillers ${ }^{1}$, Claude Poleunis ${ }^{3}$, Arnaud Delcorte ${ }^{3}$, \\ Pietro Moggi ${ }^{4}$, Gustaaf Van Tendeloo ${ }^{2}$ and Sophie Hermans ${ }^{*} 1, \S$
}

\author{
Full Research Paper \\ Address: \\ ${ }^{1}$ Institute of Condensed Matter and Nanosciences (IMCN), Université \\ catholique de Louvain, Place Louis Pasteur 1/3, B-1348 \\ Louvain-la-Neuve, Belgium, ${ }^{2}$ EMAT (Electron Microscopy for \\ Materials Science), University of Antwerp, Groenenborgerlaan 171, \\ B2020 Antwerpen, Belgium, ${ }^{3}$ Institute of Condensed Matter and \\ Nanosciences (IMCN), Université catholique de Louvain, Croix du \\ Sud 1, B-1348 Louvain-la-Neuve, Belgium, and ${ }^{4}$ Dipartimento di \\ Chimica, Università di Parma, Parco Area delle Scienze 17/A, 43124 \\ Parma, Italy \\ Email: \\ Sophie Hermans* - Sophie.Hermans@uclouvain.be \\ * Corresponding author \\ $\S$ Fax: +32 10472330 \\ Keywords: \\ ammonia synthesis; cluster; nanofibers; nanoparticles; nanotubes \\ Beilstein J. Nanotechnol. 2015, 6, 1287-1297. \\ doi:10.3762/bjnano.6.133 \\ Received: 18 March 2015 \\ Accepted: 08 May 2015 \\ Published: 10 June 2015 \\ Associate Editor: P. Ziemann \\ (C) 2015 Vidick et al; licensee Beilstein-Institut. \\ License and terms: see end of document.
}

\footnotetext{
Abstract

Heterometal clusters containing $\mathrm{Ru}$ and $\mathrm{Au}, \mathrm{Co}$ and/or Pt are anchored onto carbon nanotubes and nanofibers functionalized with chelating phosphine groups. The cluster anchoring yield is related to the amount of phosphine groups available on the nanocarbon surface. The ligands of the anchored molecular species are then removed by gentle thermal treatment in order to form nanoparticles. In the case of Au-containing clusters, removal of gold atoms from the clusters and agglomeration leads to a bimodal distribution of nanoparticles at the nanocarbon surface. In the case of $\mathrm{Ru}-\mathrm{Pt}$ species, anchoring occurs without reorganization through a ligand exchange mechanism. After thermal treatment, ultrasmall $(1-3 \mathrm{~nm}$ ) bimetal Ru-Pt nanoparticles are formed on the surface of the nanocarbons. Characterization by high resolution transmission electron microscopy (HRTEM) and high angle annular dark field scanning transmission electron microscopy (HAADF-STEM) confirms their bimetal nature on the nanoscale. The obtained bimetal nanoparticles supported on nanocarbon were tested as catalysts in ammonia synthesis and are shown to be active at low temperature and atmospheric pressure with very low Ru loading.
} 


\section{Introduction}

Metal nanoparticles (NPs) supported on nanoscopic forms of carbon (nanotubes, nanofibers) are an important class of nanostructured materials that find applications in a wide range of areas [1-5] due to the unique properties of the nanocarbons (conductivity, mechanical resistance, high surface area, etc.) combined with the size-dependent properties of the metal NPs. Due to the excellent electrical conductivity of carbon, NPs/ nanocarbons are widely used in electrochemical devices where metal/carbon nanostructured materials can be used as superior electrodes [4]. Ultrasmall metal nanoparticles are desired in order to increase (electro-)catalytic activity by increasing the active metal surface. This is especially important in the case of precious metals. Moreover, bimetal nanoparticles supported on nanocarbons have attracted much interest since synergetic effects could enhance the global activity, as compared with pure metal.

In particular, Ru-Pt NPs supported on carbon nanotubes (CNT) (mostly multiwalled nanotubes (MWNT), or carbon nanofibers (CNF)) are well suited as anodes for direct methanol fuel cells (DMFC) [6-9], which hold much prospect as a portable energy source for mobile devices. The electrocatalytic activity of $\mathrm{Pt}-\mathrm{Ru} / \mathrm{CNF}$ [7] or Pt-Ru/MWNT [10] composite electrodes for methanol oxidation is found to be better than that of commercial $\mathrm{Pt}-\mathrm{Ru} / \mathrm{C}$ catalysts. The preparation methods for $\mathrm{Pt}-\mathrm{Ru} /$ nanocarbon are varied and take inspiration from (i) electrochemistry (electrodeposition) [11,12], (ii) nanoparticle synthesis (polyol procedure) $[13,14]$ or (iii) heterogeneous catalysis (impregnation/reduction). A fixed $\mathrm{pH}$ value during the polyol process has been found to influence the nanoparticle size, composition, and catalytic activity [15]. In addition, other effects have been studied, such as the presence of oxygenated groups on MWNTs introduced by acid pretreatment [16], the Pt to $\mathrm{Ru}$ atomic ratio $[17,18]$, the lengths and diameters of the MWNTs used [19] and the type of CNT (single-, double- or multi-walled nanotubes) considered [20]. Bimetal Ru-Pt catalysts for the hydrogenation of cinnamaldehyde were prepared by impregnation of carbon nanotubes, graphite nanofibers (GNFs) and activated carbon (AC) for comparison [21]. It was found that their average particle size follows the sequence of GNF $<$ MWNT $\approx$ SWNT $<$ AC, but the activity and selectivity are sensitive to other factors such as porosity and surface chemistry of the carbon support [21,22]. Finally, alternative preparation methods have also been reported, including supercritical carbon dioxide $[23,24]$, ultrasonic treatment $[25,26]$ or $\mathrm{H}_{2}$ plasma treatment [27], for instance. Glucose sensors based on $\mathrm{PtRu} / \mathrm{MWNT}$ have been elaborated as well [28]. These studies on $\mathrm{Ru}-\mathrm{Pt} / \mathrm{MWNT}$ materials give at best global EDX analyses $[10,11,17]$ and XPS results [15]. However, these are both elemental analyses, and do not prove that both metals are mixed locally within each nanoparticle. In some other cases, powder XRD proved alloy formation [25], but this is only applicable for crystalline nanoparticles that are usually $>3 \mathrm{~nm}[13,23,29]$.

In this paper, we explore the possibility of using molecular mixed-metal clusters as precursors for depositing heterometal nanoparticles on carbon nanotubes and nanofibers. The advantages of such precursors are that they present well-defined molecular structures and exchangeable ligands, the metal atoms are in the zero oxidation state and bimetal associations can be synthesized with a large degree of freedom. This ensures the intimate mixing of the metals when nucleating heterometal nanoparticles by thermal treatment. Because this treatment only requires removing the ligand sheath, ultrasmall, mixed-metal entities directly derived from the cluster cores might be expected. For that purpose, MWNTs and CNFs functionalized with chelating phosphine groups are used as supports. The clusters that were reacted with functionalized nanocarbon surfaces included: homometal $\mathrm{Ru}$, hetero-bimetal $\mathrm{Ru}-\mathrm{M}(\mathrm{M}=\mathrm{Au}$, $\mathrm{Pt}, \mathrm{Co}$ ) and a hetero-trimetal $\mathrm{Ru}-\mathrm{Au}-\mathrm{Pt}$ species of general formula $\left[\mathrm{Ru}_{x} \mathrm{M}_{y} \mathrm{C}(\mathrm{CO})_{z} \mathrm{~L}_{z}\right]$ where $\mathrm{M}=\mathrm{Pt}$ or $\mathrm{Au}$ and $\mathrm{L}=\mathrm{COD}$ (1,5-cyclooctadiene) or $\mathrm{PPh}_{3}$ [30-36]. The letter $\mathrm{M}$ is used to designate the second metal present in the ruthenium-based bi(tri)metal cluster core. Only the $\mathrm{Ru}-\mathrm{Co}$ cluster is negatively charged and hence presents a counterion, bis(triphenylphosphine)iminium $\left(\mathrm{PPN}^{+}\right)$, giving the formula $\mathrm{PPN}\left[\mathrm{Ru}_{3} \mathrm{Co}(\mathrm{CO})_{13}\right]$. It is known that all these clusters can exchange $\mathrm{CO}$ or COD ligands with phosphine ligands [37]. In addition, the negatively charged $\mathrm{Ru}-\mathrm{Co}$ species can also interact with a support functionalized with positively charged ammonium groups $\left(-\mathrm{NMe}_{3}{ }^{+}\right)$ [38]. The bimetal $\mathrm{Ru}-\mathrm{Pt}$ association is justified by possible applications in fuel cells as described above, while $\mathrm{Au}$ is also considered in this study since Au NPs supported on nanocarbons can be used as sensors for the detection of gases or various life-related molecules such as glucose [4]. The amount of clusters that can be loaded onto a nanocarbon structure will be evaluated, as well as their behavior during the first steps of thermal treatment, which aims to gently remove the ligands and coalesce the metal cores to form ultrasmall heterometal nanoparticles supported on nanocarbons. It is generally believed that the clusters first lose their ligands, accompanied by an increased interaction with the surface, and then agglomerate with prolonged heat treatment [39-41]. This study is dedicated to the first stage of activation, i.e., denuded cluster cores before agglomeration, and in particular, their characterization at atomic resolution to prove their bimetal nature within individual nanoparticles. In order to test their potential application in catalysis, the carbon-supported nanoparticles are evaluated in ammonia synthesis, as a reference reaction with mature technology. The goal is not to optimize the catalytic performance but rather to 
demonstrate proof-of-principle activity in a well-known reaction.

The synthesis of ammonia from its constituting elements $\left(\mathrm{N}_{2}+3 \mathrm{H}_{2}\right)$ is one of the largest industrial processes based on heterogeneous catalysis [42]. Owing to the extreme inertness of $\mathrm{N}_{2}$, its chemical transformation commonly requires remarkably drastic conditions. Thus, even after extensive improvements, the industrial process of producing $\mathrm{NH}_{3}$ from $\mathrm{N}_{2}$ and $\mathrm{H}_{2}$ gas still requires very high pressures $(15-35 \mathrm{MPa})$ and temperatures $\left(400-550^{\circ} \mathrm{C}\right)[43,44]$. Therefore, the catalytic synthesis of ammonia under milder conditions has been a longstanding goal in catalysis. The early development of catalysts for ammonia synthesis was based on iron. Only Ru has been found to be a suitable alternative material and became the second generation catalyst for ammonia synthesis. While pure $\mathrm{Ru}$ is practically inactive, the addition of s-block metals $(\mathrm{K}, \mathrm{Cs}, \mathrm{Ba})$ dramatically enhances the ammonia yield [45-47]. Generally, the highest catalytic activities are obtained with carbon supports, and particularly with partially graphitized carbons [48]. Promoted $\mathrm{Ru}$ catalysts are active but more expensive than iron, hence other alternatives such as cobalt were explored [49]. Zhenwei et al. have studied supported $\mathrm{Ru}-\mathrm{M}(\mathrm{M}=\mathrm{Fe}, \mathrm{Co}, \mathrm{Ni}$, Mo) with potassium as a promoter for ammonia synthesis [50]. They found that the $\mathrm{Ru}-\mathrm{Co}$ catalysts have the highest activity, hence we incorporated this bimetal association in our study for comparison. Nanocarbon-supported catalysts have already been reported in the literature for this reaction, allowing for a benchmark for our systems. In this paper, electrochemical applications were not explored in order to avoid issues related to sample preparation and the presence of additives, binders, etc.

\section{Results and Discussion \\ Cluster anchoring}

Phosphine-functionalized carbon nanofibers and nanotubes were prepared in several steps, as previously reported [38] and shown in Figure 1. We have also successfully applied this methodology to ordered mesoporous carbon [51]. Briefly, the number of oxygenated surface functional groups is increased first by $\mathrm{HNO}_{3}$ oxidation and quantified by XPS and elemental analysis. Then, the carboxylic acid groups are reacted with $\mathrm{SOCl}_{2}$, before coupling with ethylenediamine. Finally, the pendant amine functions are transformed into bidentate chelating phosphines by the combined action of formaldehyde and diphenylphosphine or into charged ammonium groups by quaternization [38,51]. The final supports, denoted as $\mathrm{CNF}-\mathrm{PPh}_{2}$ (or $\mathrm{CNF}-\mathrm{NMe}_{3}{ }^{+}$in the case of ammonium groups) and $\mathrm{MWNT}-\mathrm{PPh}_{2}$, are characterized by XPS, elemental analysis and nitrogen adsorption isotherms. XPS reveals the presence of the expected heteroatoms at each step of the functionalization strategy and indicates (from the ratios of atom \% on the surface) that each reaction did not proceed with $100 \%$ yield and some unreacted sites remained from the previous step. The textural properties of the different supports were measured by nitrogen adsorption. The specific surface area $\left(S_{\mathrm{BET}}\right)$ of oxidized carbon nanofibers (CNFox) was found to be $43 \mathrm{~m}^{2} / \mathrm{g}$, $32 \mathrm{~m}^{2} / \mathrm{g}$ for CNF- $\mathrm{PPh}_{2}, 29 \mathrm{~m}^{2} / \mathrm{g}$ for $\mathrm{CNF}-\mathrm{NMe}_{3}{ }^{+}$, while much larger values of $325 \mathrm{~m}^{2} / \mathrm{g}$ for oxidized carbon nanotubes (MWCNTox) and $241 \mathrm{~m}^{2} / \mathrm{g}$ for MWCNT- $\mathrm{PPh}_{2}$ were found. Elemental analyses of the final $\mathrm{CNF}-\mathrm{PPh}_{2}$ and $\mathrm{MWNT}-\mathrm{PPh}_{2}$ supports reveal a $\mathrm{P} / \mathrm{C}$ ratio (mass) equal to 0.005 and 0.013 , corresponding to $\approx 1.5$ and $\approx 0.45$ anchoring sites per $\mathrm{nm}^{2}$, respectively.

Clusters 1 to $\mathbf{9}$, comprised of $\mathrm{Ru}$ and $\mathrm{Pt}, \mathrm{Co}$ and/or Au, were prepared as described in the Experimental section and are identified by their infrared $v_{\mathrm{CO}}$ bands (Table S1 in Supporting Information File 1). In our previous related publications [38,51], these clusters were reacted with the functionalized ordered mesoporous carbon but not nanotubes and nanofibers. In order to prove the necessity of functionalizing the carbonaceous surfaces to obtain cluster loading, $\mathrm{Ru}_{5} \mathrm{PtC}(\mathrm{CO})_{14}(\mathrm{COD})$ (4) and $\mathrm{Ru}_{6} \mathrm{C}(\mathrm{CO})_{16}\left(\mathrm{Au}\left\{\mathrm{PPh}_{3}\right\}\right)_{2}(\mathbf{5})$ were selected as illustrative examples and contacted with pristine or oxidized (denoted as "ox") CNF and MWNT. In all cases, the loading yield was experimentally determined. The loading yield is defined as the ratio between the amount of metal loaded onto the support (determined by ICP analysis of the solid) and the amount of metal introduced at the start (known). The solids are recovered by filtration thus any nonreacted cluster remains in solution and is

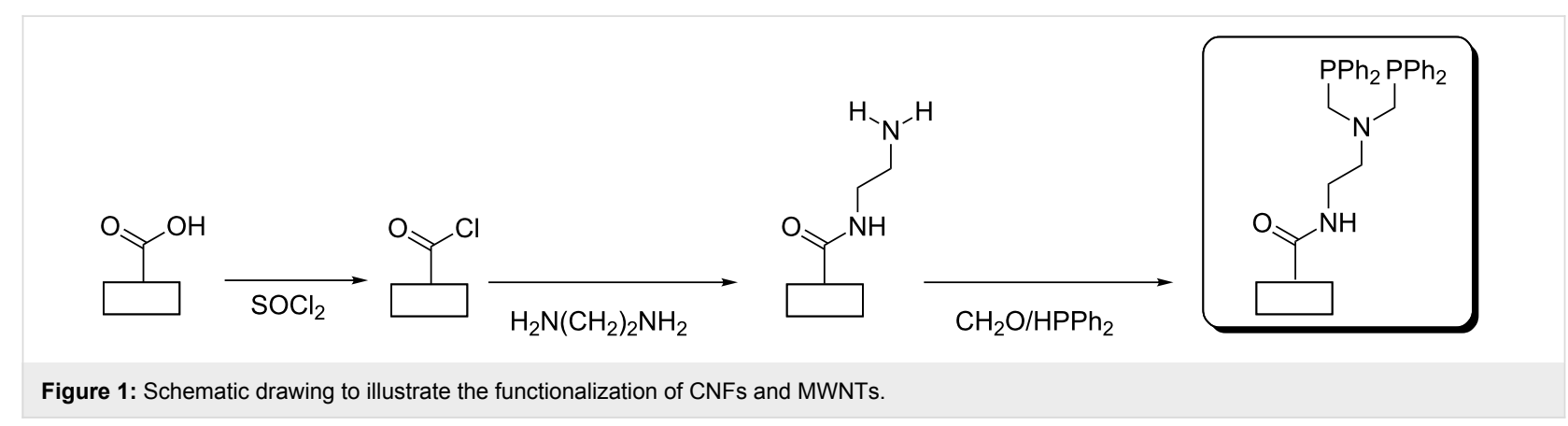


not analyzed by ICP. For cluster $\mathbf{4}$, there is no loading $(0 \%)$ on pristine supports and CNFox but $37 \%$ loading is observed on MWNTox. In the case of $\mathbf{5}$, there is no loading on pristine or oxidized supports (loading yield $=0 \%$ ).

The analyzed results clearly show that the functionalization is important for an effective loading of clusters on the CNFs and MWNTs nanocarbons. Oxygen-containing groups were not functionalized because these organometallic clusters are not oxophilic. Phosphine functionalization is necessary to ensure anchoring. Given that the anchoring process happens by ligand exchange at the surface, the driving force is the chelating ability of the bidentate phosphine groups. Indeed, we previously carried out extensive studies with the same ligands on activated carbon and obtained formal proof of the ligand exchange in the starting cluster and binding through new M-P bonds at the surface. This proof was obtained by secondary ion mass spectrometry (SIMS) by comparison with non-functionalized carbon samples, but also by reacting model compounds in solution and crystallizing the products to solve their crystal structure, confirming the hypothesis [52].

Indeed, clusters 1-9 are anchored on the phosphine-functionalized nanocarbons by stirring in a mixture of toluene and dichloromethane. Toluene is chosen to maximize interactions with the carbon support and dichloromethane to ensure solubilization of the metal species. The total metal loading is determined in each case by Ru, Co, Pt and/or Au ICP analysis of the solid and the anchoring yield calculated as defined above (loading yield). The negatively charged cluster $\mathrm{PPN}\left[\mathrm{Ru}_{3} \mathrm{Co}(\mathrm{CO})_{13}\right](9)$ is anchored with $28 \%$ yield on either a $\mathrm{CNF}-\mathrm{PPh}_{2}$ or $\mathrm{CNF}-\mathrm{NMe}_{3}{ }^{+}$support. This is logical because it can either undergo a $\mathrm{CO} /$ phosphine ligand exchange (on
$\mathrm{CNF}-\mathrm{PPh}_{2}$ ) or form an ion pair by electrostatic interactions (on $\mathrm{CNF}-\mathrm{NMe}_{3}{ }^{+}$). For species 1-8 (Figure 2), the anchoring yield is always better on $\mathrm{MWNT}-\mathrm{PPh}_{2}$ than on $\mathrm{CNF}-\mathrm{PPh}_{2}$. This result is explained by the fact that the amount of phosphine groups is higher on MWNT than on CNF (P/C determined by bulk elemental analysis, 0.013 and 0.005 , respectively). The best anchoring yield is obtained for $\mathrm{Ru}_{5} \mathrm{PtC}(\mathrm{CO})_{14}(\mathrm{COD})$ (4) while the lowest is obtained for $\mathrm{Ru}_{4} \mathrm{C}(\mathrm{CO})_{12}\left(\mathrm{Au}\left\{\mathrm{PPh}_{3}\right\}\right)_{2}$ (7). This is due to the presence of an exchangeable COD ligand in the first case and the presence of the bulky Au/phosphine groups in the second case. Clusters containing gold in general lead to lower anchoring yields for the same reason. The presence of bulky phosphine groups causes steric repulsion and disfavors the cluster approach on the carbon surface. Moreover, $\mathrm{Au}$ presents a linear coordination geometry, hence, it binds to a terminal rather than chelating phosphine ligands. It is also known that $\mathrm{Au}$ atoms in clusters actually behave more as ligands than as part of the cluster core [53].

\section{SIMS characterization of anchored species}

Cluster 4 anchored on $\mathrm{CNF}-\mathrm{PPh}_{2}$, MWNTox and MWNT- $\mathrm{PPh}_{2}$ was characterized by secondary ion mass spectrometry (SIMS) after anchoring. It should be pointed out that the SIMS analysis was difficult because of undesired electrostatic interactions in the very narrow acceleration section (a few millimeters) between the grounded sample and the extraction lens of the spectrometer at $2 \mathrm{kV}$. These point effects can be explained by the elongated shape of the CNTs and CNFs. The molecular peak corresponding to the intact cluster was not observed. This could have been an indication of the fact that it is transformed by the anchoring process. However, both metals and some fragments are detected by SIMS at the surface, which indicates in this case that the cluster has not lost its molecular

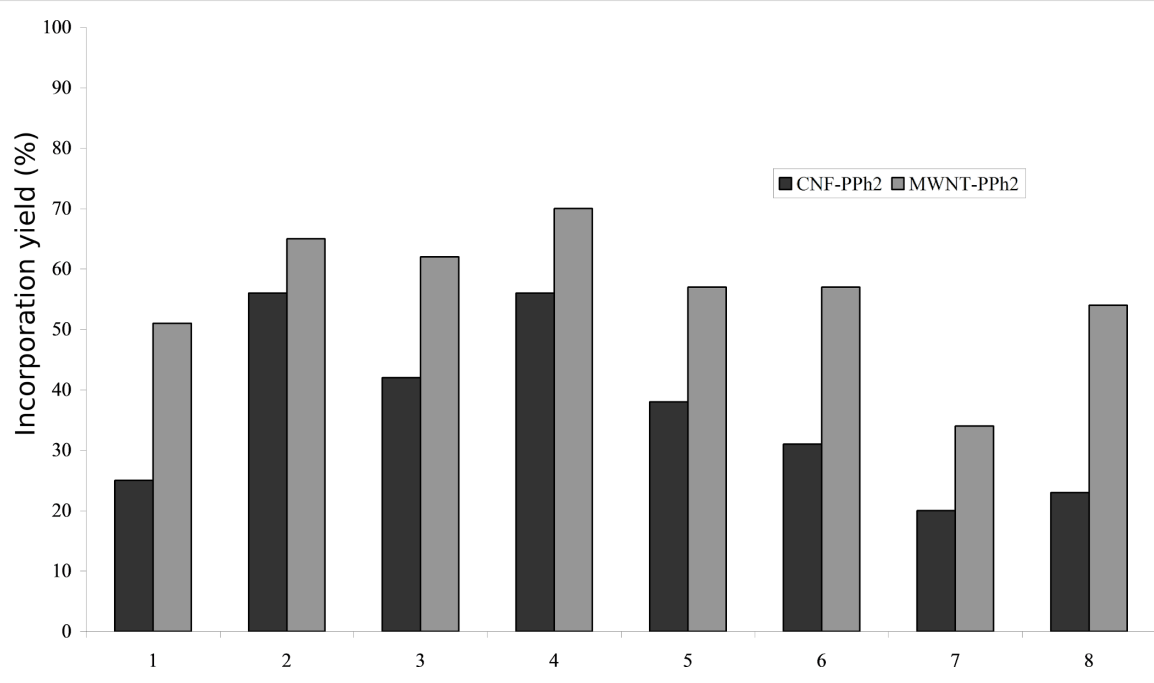

Figure 2: Anchoring yield (\%) of clusters 1 to 8 on $\mathrm{CNF}-\mathrm{PPh}_{2}$ and $\mathrm{MWNT}-\mathrm{PPh}_{2}$. 
integrity. For example, on the positive mode, an isotopic peak centered at $\mathrm{m} / \mathrm{z} 302$ is observed in the SIMS spectra of $\mathrm{Ru}_{5} \mathrm{PtC}(\mathrm{CO})_{14}(\mathrm{COD})$ (4) on $\mathrm{CNF}-\mathrm{PPh}_{2}$ (Figure $\mathrm{S} 1$ in Supporting Information File 1) that corresponds to $\left(\mathrm{PtPC}_{6} \mathrm{H}_{4}\right)^{+}$. The same fragment is also observed with the same cluster on the MWNT- $\mathrm{PPh}_{2}$ support. The $\mathrm{PC}_{6} \mathrm{H}_{4}$ moiety originates from the phosphine functions introduced beforehand on the support that have reacted with the cluster. As mentioned above, the surface ligand substitution mechanism was already studied in more detail by SIMS as well as model compounds in solution on activated carbon functionalized with the same chelating phosphines [52]. It was shown to take place effectively to give covalent anchoring of the cluster in a molecular form via metal-phosphorus bonds.

\section{Thermal activation}

Thermogravimetric analysis of the pure clusters was carried out to determine the required activation temperature to remove the ligand layer surrounding the clusters (Table S2, Supporting Information File 1). The selected temperature was $300{ }^{\circ} \mathrm{C}$ for clusters 1 to $4,350{ }^{\circ} \mathrm{C}$ for clusters 5 to 8 and $400{ }^{\circ} \mathrm{C}$ for cluster 9, for a duration of one hour, under nitrogen, in all cases. This corresponds to the removal of all ligands to produce naked clusters for species $\mathbf{1}$ to $\mathbf{4}$. Clusters 5 to 9 loose their ligands more gradually over a wider temperature range $\left(800-900{ }^{\circ} \mathrm{C}\right)$. However, they were not activated at such high temperatures to avoid sintering.

\section{XPS analysis}

The $\mathrm{Ru}-\mathrm{M}(\mathrm{M}=\mathrm{Au}, \mathrm{Pt})$ samples were characterized by XPS before and after thermal treatment to compare the various clusters with same metal nature but different composition. This study is thus not carried out for the unique $\mathrm{Ru}-\mathrm{Co}$ species. The surface M/C ratios were determined (Table S3 in Supporting Information File 1). With CNF having a diameter of about $100 \mathrm{~nm}$, XPS analysis is in this case clearly restricted to the surface (approximately $5 \mathrm{~nm}$ analysis depth for our experimental conditions). The XPS surface $\mathrm{M} / \mathrm{C}$ ratios for clusters on $\mathrm{CNF}$ are always higher than the calculated values, indicating that the clusters are located on the external surface. The experimental XPS values obtained in the case of clusters anchored on MWNTs are very similar to the calculated values. Given the small diameter of MWNTs used here $(\approx 10 \mathrm{~nm})$ and the depth of XPS analysis $(\approx 5 \mathrm{~nm})$, we ascribe this observation to the fact that XPS behaves as a bulk elemental analysis technique for MWNTs. After thermal activation, most M/C ratio values decrease slightly, indicating that agglomeration occurred but to a limited extent. This process is more important for Au-based clusters (clusters 5 to 8 ).

The $\mathrm{Ru} / \mathrm{M}$ ratios were also determined by ICP and XPS (Table 1). The experimental ratios measured by ICP are relatively close to the theoretical values, as expected. There is a systematic error due to the known difficulties regarding $\mathrm{Ru}$ dissolution. Therefore, we conclude that clusters when broken down give fragments that all remain on the support but might segregate into separate entities. This correlates with the fact that when analyzing the loading solutions after filtration using infrared spectroscopy, we usually find the unreacted (unloaded) cluster in its intact molecular form. The experimental XPS values are quite different from the theoretical values, especially in the case of gold-containing clusters. This difference is explained by cluster fragmentation on the surface and confirms the above-mentioned conclusion.

\begin{tabular}{|c|c|c|c|c|c|}
\hline \multirow[t]{2}{*}{ Cluster } & \multirow[t]{2}{*}{ Support } & \multirow[t]{2}{*}{ Ru/M calc. } & \multirow[t]{2}{*}{ Ru/M from ICP (mol) } & \multicolumn{2}{|c|}{ Ru/M from XPS } \\
\hline & & & & Before activation & After activation \\
\hline \multirow[t]{2}{*}{3} & $\mathrm{CNF}-\mathrm{PPh}_{2}$ & $6(\mathrm{Pt})$ & 4.99 & 3.25 & 2.50 \\
\hline & MWNT-PPh 2 & & 5.05 & 2.25 & 1.46 \\
\hline \multirow[t]{2}{*}{4} & $\mathrm{CNF}-\mathrm{PPh}_{2}$ & $5(\mathrm{Pt})$ & 4.37 & 3.16 & 2.43 \\
\hline & MWNT-PPh 2 & & 4.52 & 3.34 & 2.02 \\
\hline \multirow[t]{2}{*}{5} & $\mathrm{CNF}-\mathrm{PPh}_{2}$ & $3(\mathrm{Au})$ & 2.12 & 1.86 & 2.89 \\
\hline & MWNT-PPh 2 & & 2.61 & 1.32 & 2.08 \\
\hline \multirow[t]{2}{*}{6} & $\mathrm{CNF}-\mathrm{PPh}_{2}$ & $2.5(\mathrm{Au})$ & 2.01 & 1.36 & 4.72 \\
\hline & MWNT-PPh 2 & & 2.15 & 1.08 & 1.89 \\
\hline \multirow[t]{2}{*}{7} & $\mathrm{CNF}-\mathrm{PPh}_{2}$ & $2(\mathrm{Au})$ & 1.60 & 0.80 & 4.00 \\
\hline & MWNT-PPh 2 & & 1.91 & 0.72 & 1.56 \\
\hline \multirow[t]{4}{*}{8} & $\mathrm{CNF}-\mathrm{PPh}_{2}$ & $5(\mathrm{Pt})$ & 4.59 & 2.98 & 3.03 \\
\hline & & $2.5(\mathrm{Au})$ & 1.60 & 1.01 & 3.90 \\
\hline & MWNT-PPh 2 & $5(\mathrm{Pt})$ & 4.40 & 0.78 & 0.41 \\
\hline & & $2.5(\mathrm{Au})$ & 1.54 & 0.45 & 0.75 \\
\hline
\end{tabular}




\section{TEM investigations at low magnification}

Low magnification transmission electron microscopy (TEM) imaging is used to determine particle sizes after activation and to image their dispersion. TEM images of clusters $\mathbf{1}$ to $\mathbf{3}$ on $\mathrm{MWNT}-\mathrm{PPh}_{2}$ (Figure $\left.3 \mathrm{a}-\mathrm{c}\right)$ reveal that nanoparticles with diameters of $1-3 \mathrm{~nm}$ are homogeneously dispersed on CNTs. Cluster 4 on $\mathrm{MWNT}-\mathrm{PPh}_{2}$ (Figure $3 \mathrm{f}$ ) or $\mathrm{CNF}-\mathrm{PPh}_{2}$ (Figure 3d,e) exhibits particles with diameters $<2 \mathrm{~nm}$. Even if the final particles are ultrasmall, limited agglomeration occurred during thermal activation as the final particles sizes are slightly larger than the size of a single cluster $(\approx 0.4 \mathrm{~nm})$. The ligand substitution strategy for anchoring and stabilization of clusters is thus efficient in the case of $\mathrm{Ru}$ or $\mathrm{Ru}-\mathrm{Pt}$ clusters.

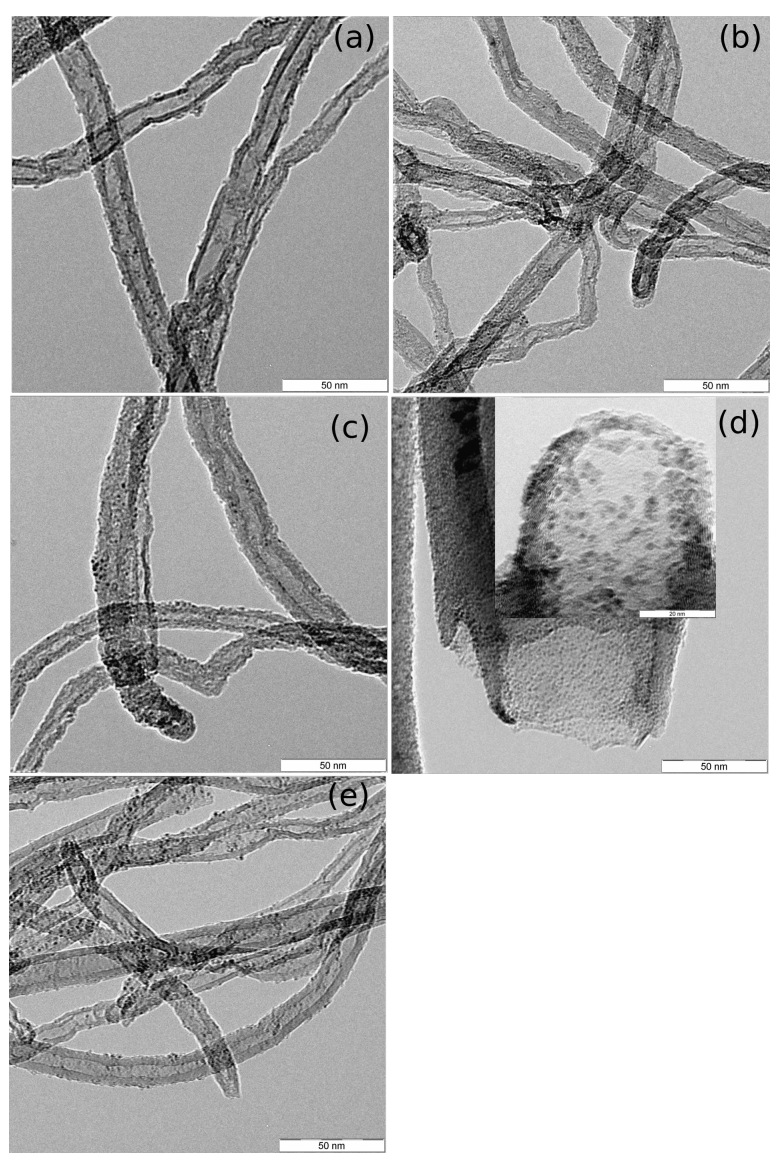

Figure 3: TEM images of clusters 1 to 3 on MWNT-PPh 2 after therma treatment (a) $\mathrm{Ru}_{6} \mathrm{C}(\mathrm{CO})_{17}$ (1), (b) $\mathrm{Ru}_{5} \mathrm{C}(\mathrm{CO})_{15}$ (2), (c) $\mathrm{Ru}_{6} \mathrm{PtC}-$

$(\mathrm{CO})_{16}(\mathrm{COD})(3)$, and of cluster $\mathrm{Ru}_{5} \mathrm{PtC}(\mathrm{CO})_{14}(\mathrm{COD})(4)$ after thermal treatment (d) on $\mathrm{CNF}-\mathrm{PPh}_{2}$ (inset at higher magnification) and $(\mathrm{e})$ on MWNT-PPh .

TEM images of cluster 5 introduced on CNF- $\mathrm{PPh}_{2}$ (Figure S2a, Supporting Information File 1) show well-dispersed nanoparticles smaller than $3 \mathrm{~nm}$, with accompanying presence of larger particles of 8-12 nm diameter as well. The same observations can be made with phosphine-functionalized nanotubes (Figure
S2b Supporting Information File 1). These larger particles were analyzed by EDXS (Figure S2f, Supporting Information File 1), and it was revealed that these particles are constituted of $\mathrm{Au}$ only. Ru was found in the zones where the smallest particles $(<3 \mathrm{~nm})$ were found. The anchoring of these clusters on phosphine-functionalized supports causes its fragmentation. Similar results were previously observed on activated carbon [52], where it was shown that the cluster lost one Au atom during its anchoring on the support. During thermal treatment, these $\mathrm{Au}$ atoms tend to aggregate into larger particles.

The TEM images of the other Au-containing clusters 6 to 8 on MWNT- $\mathrm{PPh}_{2}$ (Figure S2c-e Supporting Information File 1) also show ultrasmall particles with diameters $<3 \mathrm{~nm}$ and larger particles of different sizes depending on the cluster. For $\mathrm{Ru}_{5} \mathrm{Au}_{2} \mathrm{C}(\mathrm{CO})_{14}\left(\mathrm{PPh}_{3}\right)_{2}(6)$, the size distribution of the large particles range between 15 and $20 \mathrm{~nm}$, between 20 and $30 \mathrm{~nm}$ for $\mathrm{Ru}_{4} \mathrm{Au}_{2} \mathrm{C}(\mathrm{CO})_{12}\left(\mathrm{PPh}_{3}\right)_{2}(7)$, and between 15 and $25 \mathrm{~nm}$ for $\mathrm{Ru}_{5} \mathrm{PtAu}_{2} \mathrm{C}(\mathrm{CO})_{15}\left(\mathrm{PPh}_{3}\right)_{2}(\mathbf{8})$. The reactivity of the molecular cluster species with the functionalized surface thus has more influence on the size of nanoparticles obtained than the choice of the initial nanocarbon material.

\section{HRTEM and HAADF-STEM studies}

In order to further study the structure of the supported $\mathrm{Ru}-\mathrm{Pt}$ nanoparticles, the sample supported on MWNTs derived from $\mathrm{Ru}_{5} \mathrm{PtC}(\mathrm{CO})_{14}(\mathrm{COD})(4)$ is characterized by high resolution transmission electron microscopy (HRTEM) and high angle annular dark field scanning transmission electron microscopy (HAADF-STEM) using aberration-corrected transmission electron microscopy (AC-TEM). HRTEM images of nanoparticles derived from cluster 4 reveal that they are not well crystallized (Figure 4a). This is due to the low temperature treatment applied for removing the ligands. In Figure $4 b$, an amorphous layer is observed around the nanoparticle, which is very likely due to the incomplete removal of ligands. The lack of crystallinity and amorphous layer coating might be detrimental for
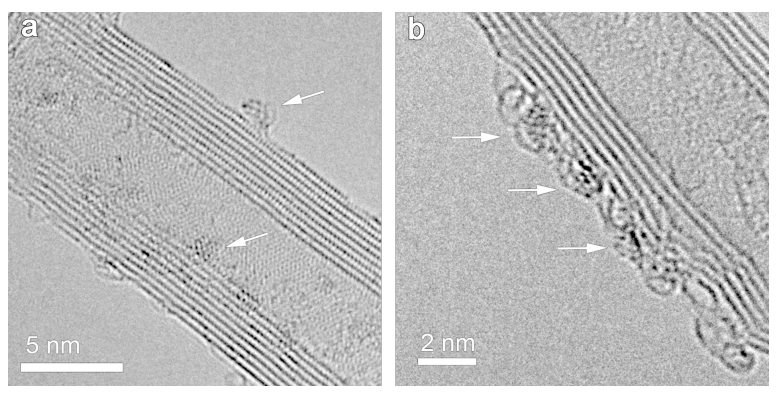

Figure 4: HRTEM images (Cs-corrected) of Ru-Pt/MWNT derived from $\mathrm{Ru}_{5} \mathrm{PtC}(\mathrm{CO}){ }_{14}(\mathrm{COD})$ (4) cluster. (a) Metal nanoparticles are indicated by arrows, (b) an amorphous layer can be seen around the nanoparticles at higher magnification. 
catalytic activity but could be overcome by higher temperature treatment. We have tested temperatures up to $1300^{\circ} \mathrm{C}$ and these lead only to moderate agglomeration to reach particle sizes in the $10-15 \mathrm{~nm}$ range. This moderate agglomeration is due to stabilization by the anchoring arm.

In order to confirm the presence of the $\mathrm{Ru} / \mathrm{Pt}$ bimetal nanoparticles, the sample was investigated using aberration-corrected HAADF-STEM and STEM energy dispersive X-ray (EDX) analysis. In HAADF-STEM, the intensity scales with the atomic number, $Z$. Therefore, the heavy elements in the nanoparticles, namely Pt and $\mathrm{Ru}$, appear as bright contrast features. As shown in Figure 5, metal nanoparticles appear as a white contrast at atomic resolution. In addition, free standing individual atoms are visible on the CNT surface as well, which is likely to be caused by cluster collapse. This finding is important as it is generally believed that during thermal treatment the clusters lose their ligands before aggregating. Here we provide direct evidence for cluster fragmentation before agglomeration at the first stages of thermal activation. This was not expected as this $\mathrm{Ru}-\mathrm{Pt}$ species was covalently anchored with molecular integrity before being submitted to activation.

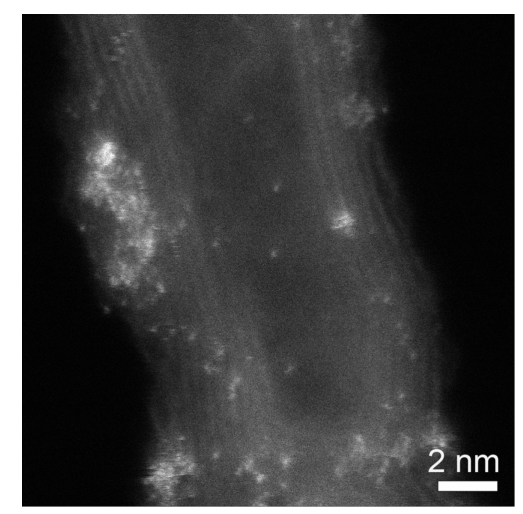

Figure 5: HAADF-STEM image of Ru-Pt/MWNT derived from $\mathrm{Ru}_{5} \mathrm{PtC}(\mathrm{CO})_{14}(\mathrm{COD})(4)$.

In order to confirm the elemental composition of the ultrasmall nanoparticles, STEM-EDX spot analysis is performed over individual nanoparticles of diameter of approximately $2-3 \mathrm{~nm}$, as shown in Figure 6a. The EDX spectrum taken from spot 1 confirms the presence of both $\mathrm{Ru}$ and $\mathrm{Pt}$ where $\mathrm{Ru}$ contributes more dose than Pt (Figure 6c). This is in agreement with a $\mathrm{Ru} / \mathrm{Pt}$ 5:1 stoichiometry in the starting cluster. However, for ultrasmall nanoparticles, as indicated with spot 2 (approximately $1 \mathrm{~nm}$ in diameter), only $\mathrm{Ru}$ is detectable (Figure 6d). Due to the ultrasmall size of these nanoparticles, they are damaged by electron irradiation and disappear after the spectra acquisition (Figure 6b). This may explain the EDX point analysis of ultrasmall nanoparticles. The contribution of $\mathrm{Pt}$, if present, is too small or too short-lived to be confirmed. These ultrasmall particles are most probably individual cluster cores, hence containing only one $\mathrm{Pt}$ atom in each nanoparticle.

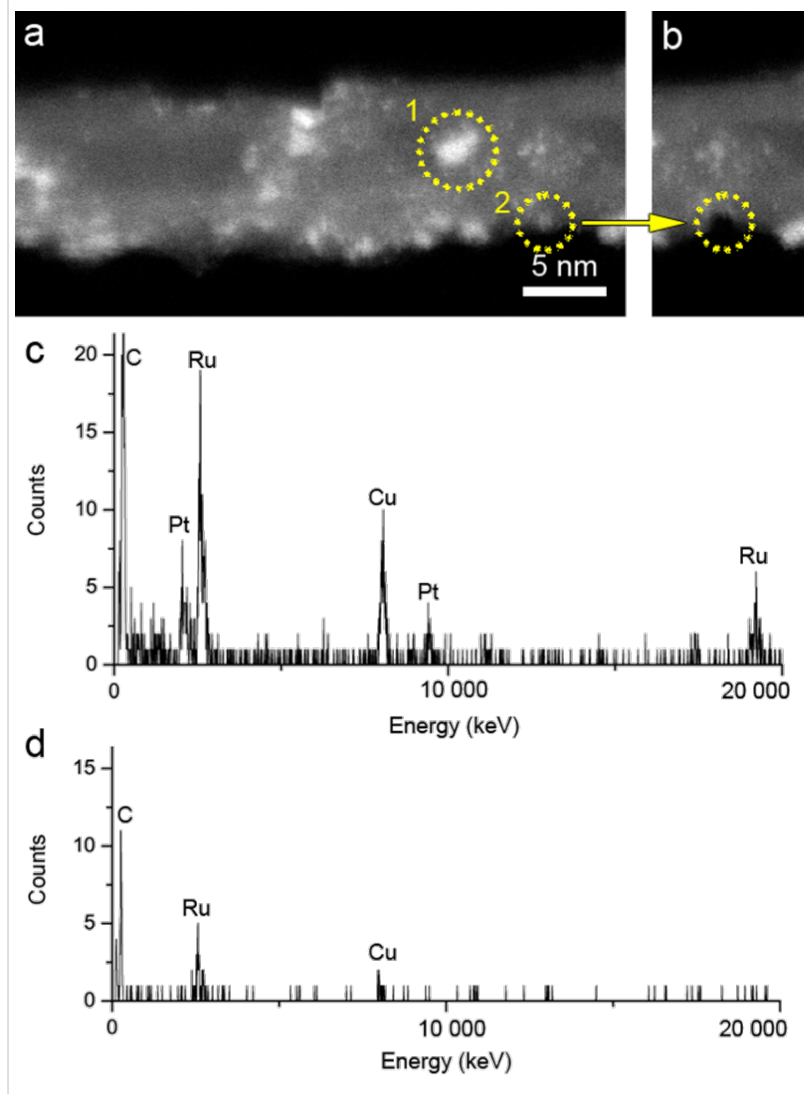

Figure 6: STEM-EDX of individual nanoclusters. (a) HAADF-STEM image of a nanotube with metal clusters. The spectra were collected from point 1 (larger particles $\approx 2-3 \mathrm{~nm}$ diameter particles) and point 2 (smaller particles $<1 \mathrm{~nm}$ ). The corresponding spectra are shown as (c) point 1 and (d) point 2. (b) HAADF-STEM image of the same nanotube after spectra acquisition. The smaller particles where the spectrum in (d) is collected has been destroyed, see circled area. (c) EDX spectrum of a larger particle, where both Pt and Ru are present, but Ru has more counts. (d) EDX spectrum of a smaller particle, where only Ru is present. Low counts are probably due to the small volume of the ultrasmall particle.

The use of single source precursors was thus adequate for the formation of heterometal nanoparticles. The presence of both metals within a single ultrasmall, non-crystalline nanoparticle is proven, which is not amenable to XRD characterization.

\section{Catalysis}

Despite the lack of crystallinity and amorphous layer coating observed by HRTEM, the obtained materials were tested as heterogeneous catalysts to demonstrate proof-of-principle activity. The reaction investigated was ammonia synthesis. This was carried out in a preliminary manner without any optimiz- 
ation of the reaction conditions. We have tested five catalysts based on $\mathrm{Ru}(-\mathrm{M})$ clusters prepared on phosphine- or ammonium-functionalized nanofibers (Table 2). The first synthesis step consisted of anchoring the Ru-based clusters on the functionalized nanofibers and subsequent thermal activation as described above. The percentage of Ru present on the carbon nanofibers at this stage was determined by ICP analysis (Table 2). In a second step, a promoter element, Cs, was added to the support by impregnation of the cesium oxalate compound followed by solvent evaporation (see Supporting Information File 1 for experimental details). The final activation under $\mathrm{H}_{2}$ was realized after determination of the experimental conditions by temperature programmed reduction (TPR). The samples were characterized by XPS and TEM after the catalytic test. Afterwards, small particles were still observed but with the concomitant presence of small agglomerates $(5-10 \mathrm{~nm})$ probably due to sintering during the catalytic test (see Figure S4 in Supporting Information File 1). The same TEM observations were made for the five catalysts.

\begin{tabular}{|c|c|c|}
\hline Precursor & Support & $\begin{array}{c}\text { Ru wt \% } \\
\text { after thermal } \\
\text { activation }\end{array}$ \\
\hline $\mathrm{Ru}_{5} \mathrm{C}(\mathrm{CO})_{15}(2)$ & $\mathrm{CNF}-\mathrm{PPh}_{2}$ & 2.3 \\
\hline $\mathrm{Ru}_{5} \mathrm{PtC}(\mathrm{CO})_{14}(\mathrm{COD})(\mathbf{4})$ & $\mathrm{CNF}-\mathrm{PPh}_{2}$ & 3.0 \\
\hline $\mathrm{Ru}_{5} \mathrm{C}(\mathrm{CO})_{14}\left(\mathrm{Au}\left\{\mathrm{PPh}_{3}\right\}\right)_{2}(\mathbf{6})$ & $\mathrm{CNF}-\mathrm{PPh}_{2}$ & 2.6 \\
\hline $\mathrm{Ru}_{5} \mathrm{PtC}(\mathrm{CO})_{15}\left(\mathrm{Au}\left\{\mathrm{PPh}_{3}\right\}\right)_{2}(\mathbf{8})$ & $\mathrm{CNF}-\mathrm{PPh}_{2}$ & 2.3 \\
\hline $\mathrm{PPN}\left[\mathrm{Ru}_{3} \mathrm{Co}(\mathrm{CO})_{13}\right](9)$ & $\mathrm{CNF}-\mathrm{NMe}_{3}^{+}$ & 1.7 \\
\hline
\end{tabular}

The catalytic tests were realized at different temperatures and the results are presented in Supporting Information File 1. Table 3 summarizes the best results obtained for each catalyst. From these results, it can be concluded that the presence of $\mathrm{Pt}$ and particularly of $\mathrm{Au}$ is negative for the production of $\mathrm{NH}_{3}$. It is known that $\mathrm{Pt}$ easily dissociates $\mathrm{H}_{2}$ which would cover the $\mathrm{Ru}$ surface by $\mathrm{H}$ making it inaccessible for $\mathrm{N}_{2}$ dissociation. These results (ammonia synthesis rate, $\mathrm{mmol} \mathrm{NH}_{3} \mathrm{~h}^{-1} \mathrm{~g}^{-1} \mathrm{Ru}$ ) are as good as or better than some results obtained on inorganic oxides supports $[54,55]$ but less $(\approx 10 \times)$ than some results reported with carbon nanotubes and nanofibers in the literature $[43,56,57]$ using different experimental catalytic testing conditions. This allows for a benchmark for our systems and shows that they are not yet highly performing. It is remarkable that significant activity was obtained although such a low temperature and at atmospheric pressure with very low Ru loading was used. The maximum Ru percentage anchored was between 2 and $3 \mathrm{wt} \%$, while a higher percentage (5-10\%) of Ru was used in reported studies to guarantee high performance. In addition, it has been shown that ultrasmall particles (1-2 nm) are less active in ammonia synthesis than larger ones (3-4 nm) [58]. In our catalysts the majority of particles have a diameter of $<2 \mathrm{~nm}$. Finally, clusters 6, 8 and 9 are characterized by a higher decomposition temperature. Therefore, the selected low activation temperature could adversely influence their catalytic activity together with residues from the functionalization $\operatorname{arm}(\mathrm{Cl}, \mathrm{S}, \mathrm{O}$, P) [59]. Thus, there is room for improvement of the catalytic performance by optimizing the thermal activation pretreatment.

\section{Conclusion}

Samples of carbon nanofibers and nanotubes were functionalized with chelating phosphine groups. Ru-based clusters were covalently anchored onto the modified carbon surfaces by ligand exchange. The characterization of the materials demonstrated the molecular nature of grafted fragments. The cluster molecules were then denuded from their ligand layer by gentle thermolysis and coalesced into metal nanoparticles of very small sizes. In the case of gold-containing clusters, a bimodal size distribution of metal nanoparticles was obtained due to gold segregation from the cluster cores and strong aggregation. In the case of $\mathrm{Ru}-\mathrm{Pt}$ precursors, heterometal nanoparticles of ultrasmall size were formed on the carbon fibers and MWNTs. We used a combination of HRTEM and STEM-EDX analysis to prove their bimetal nature on the scale of an individual nanoparticle. This demonstrated that mixed-metal clusters are suitable precursors for ultrasmall heterometal nanoparticles of controlled composition if their reactivity is taken into account. The obtained $\mathrm{Ru}-\mathrm{Pt}$ /nanocarbon composites could find application in heterogeneous catalysis or as anodes for direct methanol fuel cells. After promotion with $\mathrm{Cs}$, we showed that our $\mathrm{Ru} / \mathrm{C}$ nanocomposites are indeed active in ammonia synthesis under very mild conditions.

\begin{tabular}{|c|c|c|c|c|c|}
\hline & $2\left(225^{\circ} \mathrm{C}\right)$ & $4\left(350^{\circ} \mathrm{C}\right)$ & $6\left(375^{\circ} \mathrm{C}\right)$ & $8\left(375^{\circ} \mathrm{C}\right)$ & $9\left(300^{\circ} \mathrm{C}\right)$ \\
\hline Ammonia synthesis rate (per g cat) & 1.01 & 0.79 & 0.44 & 0.28 & 0.95 \\
\hline Ammonia synthesis rate (per $\mathrm{g} \mathrm{Ru}$ ) & 43.98 & 26.23 & 16.86 & 12.22 & 55.72 \\
\hline Ammonia production (\%) & 0.48 & 0.41 & 0.21 & 0.13 & 0.44 \\
\hline
\end{tabular}




\section{Experimental}

The experimental strategy was, in general, very similar to previous, related studies [38,51]. All steps were carried out under $\mathrm{N}_{2}$ using standard Schlenk techniques. The solvents were distilled or degassed before use, stored under nitrogen on molecular sieves, and the obtained products were stored under Ar in a glovebox. The CNFs (PR-24-XT-PS-OX, named CNFox here for simplicity) were received from Applied Sciences, Inc. (USA) and MWNTs (of 90\% C purity) were supplied by Nanocyl S.A. (Belgium). Non-carbon impurities were not found in the MWNT sample. The functionalized supports, $\mathrm{CNF}-\mathrm{PPh}_{2}$, $\mathrm{CNF}-\mathrm{NMe}_{3}{ }^{+}, \mathrm{MWNT}$ ox and $\mathrm{MWNT}-\mathrm{PPh}_{2}$, were prepared as described elsewhere [38]. All mentioned reactants were commercially available and used as received. $\mathrm{Ru}_{3}(\mathrm{CO})_{12}$ was supplied by Alfa Aesar, while $\mathrm{Au}\left(\mathrm{PPh}_{3}\right) \mathrm{Cl}$, bis(triphenylphosphine)iminium chloride (PPNCl), $\mathrm{Pt}(\mathrm{COD}) \mathrm{Cl}_{2}(\mathrm{COD}=1,5-$ cyclooctadiene) and $\mathrm{PPh}_{4} \mathrm{Cl}$ were supplied by Aldrich. The experimental setup for the physicochemical methods of characterization is described Supporting Information File 1.

\section{Synthesis of clusters}

All clusters were synthesized using a procedure outlined in the literature [30,31,33-36] except for the cluster $\mathrm{Ru}_{6} \mathrm{C}(\mathrm{CO})_{16}\left(\mathrm{Au}\left\{\mathrm{PPh}_{3}\right\}\right)_{2}(\mathbf{5})$. This cluster was prepared by reacting $100 \mathrm{mg}$ of $(\mathrm{PPN})_{2}\left[\mathrm{Ru}_{6} \mathrm{C}(\mathrm{CO})_{16}\right](0.0466 \mathrm{mmol})$ with 2 equiv of $\mathrm{Au}\left(\mathrm{PPh}_{3}\right) \mathrm{Cl}(46.1 \mathrm{mg}, 0.0933 \mathrm{mmol})$ in $10 \mathrm{~mL}$ of dichloromethane. The mixture was stirred at room temperature for $1 \mathrm{~h}$, then filtered and the solvent was removed under reduced pressure. The obtained powder was purified by column chromatography on silica (hexane/dichloromethane 50/50) to give $\mathbf{5}$ as a dark red powder. The different results of clusters characterization are summarized in Table S1 of Supporting Information File 1.

\section{Anchoring and activation of clusters}

The cluster concentration involved in each experiment corresponds to a theoretical $5 \mathrm{wt} \%$ metal loading on the support directly after ligand removal. In a typical experiment, $8.7 \mathrm{mg}$ of cluster 3, for example, was stirred with $95 \mathrm{mg}$ of $\mathrm{CNF}-\mathrm{PPh}_{2}$ or $\mathrm{MWNT}-\mathrm{PPh}_{2}$ in a 1:1 (v/v) mixture of toluene and dichloromethane (total volume of $20 \mathrm{~mL}$ ) at room temperature for 5 days in the dark. The solid was filtered out, washed with dichloromethane and dried at room temperature under vacuum. The anchoring yield was measured by direct analysis of the metal in the solid samples by ICP-AES. The anchoring yield is defined as the ratio between the amount of metal determined by ICP analysis of the solid and the known amount of metal engaged at the start in solution.

The supported clusters were then submitted to thermal treatment in a tubular oven, STF 16/450 from Carbolite. The samples were placed into porcelain combustion boats and heated under $\mathrm{N}_{2}$ stream at $300{ }^{\circ} \mathrm{C}$ for $1 \mathrm{~h}$ for cluster $\mathbf{1}$ to 4 , at $350{ }^{\circ} \mathrm{C}$ for $1 \mathrm{~h}$ for cluster 5 to 8 and at $400{ }^{\circ} \mathrm{C}$ for cluster 9 (heating ramp rate: $100{ }^{\circ} \mathrm{C} / \mathrm{h}$ ).

\section{Supporting Information}

\section{Supporting Information File 1}

Characterization of clusters, thermogravimetric analysis, tables with XPS results, SIMS spectra, TEM images and EDXS analysis, in addition to a description of physico-chemical methods of characterization (experimental details) and ammonia catalysis (synthesis, tests, results).

[http://www.beilstein-journals.org/bjnano/content/ supplementary/2190-4286-6-133-S1.pdf]

\section{Acknowledgments}

The authors gratefully acknowledge the Fonds de la Recherche Scientifique (FRS-FNRS) and the Interuniversity Attraction Pole Programme of the Belgian State (INANOMAT P6/17 project), as well as the support of Fédération Wallonie-Bruxelles and the National Lottery (FRFC) for financial support. They also acknowledge the Fonds pour la formation à la Recherche dans l'Industrie et dans l'Agriculture (FRIA) for the research fellowship allotted to D.V. They are also grateful to the Nanocyl company for supplying the MWNTs, Applied Sciences, Inc. for supplying CNF and J.-F. Statsyns for technical support. X. Ke and G. Van Tendeloo are grateful for the financial support from the European Research Council under the Seventh Framework Programme, the ERC Advanced Grant No. 246791-COUNTATOMS, and the European Union under the Seventh Framework Programe, the ESMI (No. 262348 European Soft Matter Infrastructure).

\section{References}

1. Serp, P.; Corrias, M.; Kalck, P. Appl. Catal., A 2003, 253, 337-358. doi:10.1016/S0926-860X(03)00549-0

2. Wildgoose, G. G.; Banks, C. E.; Compton, R. G. Small 2006, 2, 182-193. doi:10.1002/smll.200500324

3. Capek, I. Adv. Colloid Interface Sci. 2009, 150, 63-89. doi:10.1016/j.cis.2009.05.006

4. Wu, B.; Kuang, Y.; Zhang, X.; Chen, J. Nano Today 2011, 6, 75-90. doi:10.1016/j.nantod.2010.12.008

5. Lee, K.; Zhang, J.; Wang, H.; Wilkinson, D. P. J. Appl. Electrochem. 2006, 36, 507-522. doi:10.1007/s10800-006-9120-4

6. Liu, H.; Song, C.; Zhang, L.; Zhang, J.; Wang, H.; Wilkinson, D. P. J. Power Sources 2006, 155, 95-110. doi:10.1016/j.jpowsour.2006.01.030

7. Maiyalagan, T. Int. J. Hydrogen Energy 2009, 34, 2874-2879. doi:10.1016/j.jhydene.2009.01.069 
8. Carmo, M.; Paganin, V. A.; Rosolen, J. M.; Gonzalez, E. R. J. Power Sources 2005, 142, 169-176. doi:10.1016/j.jpowsour.2004.10.023

9. Bambagioni, V.; Bianchini, C.; Marchionni, A.; Filippi, J.; Vizza, F.; Teddy, J.; Serp, P.; Zhiani, M. J. Power Sources 2009, 190, 241-251. doi:10.1016/j.jpowsour.2009.01.044

10. Prabhuram, J.; Zhao, T. S.; Liang, Z. X.; Chen, R. Electrochim. Acta 2007, 52, 2649-2656. doi:10.1016/j.electacta.2006.09.027

11. He, Z.; Chen, J.; Liu, D.; Zhou, H.; Kuang, Y. Diamond Relat. Mater. 2004, 13, 1764-1770. doi:10.1016/j.diamond.2004.03.004

12. Tsai, M.-C.; Yeh, T.-K.; Tsai, C.-H. Electrochem. Commun. 2006, 8, 1445-1452. doi:10.1016/j.elecom.2006.07.003

13. Jeng, K.-T.; Chien, C.-C.; Hsu, N.-Y.; Yen, S.-C.; Chiou, S.-D.; Lin, S.-H.; Huang, W.-M. J. Power Sources 2006, 160, 97-104. doi:10.1016/j.jpowsour.2006.01.057

14. Liu, Z.; Ling, X. Y.; Guo, B.; Hong, L.; Lee, J. Y. J. Power Sources 2007, 167, 272-280. doi:10.1016/j.jpowsour.2007.02.044

15. Ren, L.; Xing, Y. Electrochim. Acta 2008, 53, 5563-5568. doi:10.1016/j.electacta.2008.02.109

16. Hernández-Fernández, P.; Nuño, R.; Fatás, E.; Fierro, J. L. G.; Ocón, P. Int. J. Hydrogen Energy 2011, 36, 8267-8278. doi:10.1016/j.ijhydene.2011.04.006

17. Yao, Y.-I.; Ding, Y.; Ye, L.-S.; Xia, X.-H. Carbon 2006, 44, 61-66. doi:10.1016/j.carbon.2005.07.010

18. Li, L.; Xing, Y. J. Phys. Chem. C 2007, 111, 2803-2808. doi:10.1021/jp0655470

19. Li, J.; Liang, Y.; Liao, Q.; Zhu, X.; Tian, X. Electrochim. Acta 2009, 54, 1277-1285. doi:10.1016/j.electacta.2008.09.005

20. Li, W.; Wang, X.; Chen, Z.; Waje, M.; Yan, Y. J. Phys. Chem. B 2006, 110, 15353-15358. doi:10.1021/jp0623443

21. Vu, H.; Gonçalves, F.; Philippe, R.; Lamouroux, E.; Corrias, M.; Kihn, Y.; Plee, D.; Kalck, P.; Serp, P. J. Catal. 2006, 240, 18-22. doi:10.1016/j.jcat.2006.03.003

22. Teddy, J.; Falqui, A.; Corrias, A.; Carta, D.; Lecante, P.; Gerber, I.; Serp, P. J. Catal. 2011, 278, 59-70. doi:10.1016/j.jcat.2010.11.016

23. An, G.; Yu, P.; Mao, L.; Sun, Z.; Liu, Z.; Miao, S.; Miao, Z.; Ding, K. Carbon 2007, 45, 536-542. doi:10.1016/j.carbon.2006.10.018

24. Yen, C. H.; Shimizu, K.; Lin, Y.-Y.; Bailey, F.; Cheng, I. F.; Wai, C. M. Energy Fuels 2007, 21, 2268-2271. doi:10.1021/ef0606409

25. Xu, M.-W.; Su, Z.; Weng, Z.-W.; Wang, Z.-C.; Dong, B. Mater. Chem. Phys. 2010, 124, 785-790. doi:10.1016/j.matchemphys.2010.07.061

26. Yang, C.; Hu, X.; Wang, D.; Dai, C.; Zhang, L.; Jin, H.; Agathopoulos, S. J. Power Sources 2006, 160, 187-193. doi:10.1016/j.jpowsour.2006.05.015

27. Jiang, Z.; Jiang, Z.-j. Electrochim. Acta 2011, 56, 8662-8673. doi:10.1016/j.electacta.2011.07.067

28. Xiao, F.; Zhao, F.; Mei, D.; Mo, Z.; Zeng, B. Biosens. Bioelectron. 2009, 24, 3481-3486. doi:10.1016/j.bios.2009.04.045

29. Xiong, L.; Manthiram, A. Solid State lonics 2005, 176, 385-392. doi:10.1016/j.ssi.2004.08.005

30. Nicholls, J. N.; Vargas, M. D.; Hriljac, J.; Sailor, M. Carbido-Carbonyl Ruthenium Cluster Complexes. In Inorg. Synth.; Kaesz, H. D., Ed.; 1989; Vol. 26, pp 280-285. doi:10.1002/9780470132579.ch49

31. Hermans, S.; Khimyak, T.; Johnson, B. F. G. J. Chem. Soc., Dalton Trans. 2001, 3295-3302. doi:10.1039/b105844b

32. Bruce, M. I.; Horn, E.; Humphrey, P. A.; Tiekink, E. R. T. J. Organomet. Chem. 1996, 518, 121-138. doi:10.1016/0022-328X(96)06195-5
33. Johnson, B. F. G.; Lewis, J.; Nelson, W. J. H.; Nicholls, J. N.; Puga, J.; Raithby, P. R.; Rosales, M. J.; Schröder, M.; Vargas, M. D. J. Chem. Soc., Dalton Trans. 1983, 2447-2457. doi:10.1039/dt9830002447

34. Cowie, A. G.; Johnson, B. F. G.; Lewis, J.; Raithby, P. R. J. Chem. Soc., Chem. Commun. 1984, 1710-1712. doi:10.1039/c39840001710

35. Khimyak, T.; Johnson, B. F. G.; Hermans, S.; Bond, A. D. Dalton Trans. 2003, 2651-2657. doi:10.1039/b303178k

36. Steinhardt, P. C.; Gladfelter, W. L.; Harley, A. D.; Fox, J. R.; Geoffroy, G. L. Inorg. Chem. 1980, 19, 332-339. doi:10.1021/ic50204a012

37. Hermans, S.; Khimyak, T.; Feeder, N.; Teat, S. J.; Johnson, B. F. G. Dalton Trans. 2003, 672-684. doi:10.1039/b209592k

38. Vidick, D.; Herlitschke, M.; Poleunis, C.; Delcorte, A.; Hermann, R. P.; Devillers, M.; Hermans, S. J. Mater. Chem. A 2013, 1, 2050-2063. doi:10.1039/C2TA00131D

39. Hogarth, G.; Kabir, S. E.; Nordlander, E. Dalton Trans. 2010, 39, 6153-6174. doi:10.1039/c000514b

40. Femoni, C.; lapalucci, M. C.; Kaswalder, F.; Longoni, G.; Zacchini, S. Coord. Chem. Rev. 2006, 250, 1580-1604. doi:10.1016/j.ccr.2006.03.011

41. Braustein, P.; Oro, L. A.; Raithby, P. R., Eds. Metal Clusters in Chemistry; Wiley-VCH: Weinheim, Germany, 1999. doi:10.1002/9783527618316

42. Horvath, I. T. Encyclopedia of Catalysis; John Wiley \& Sons: Hoboken, NJ, USA, 2003; Vol. 1.

43. Liang, C.; Wei, Z.; Xin, Q.; Li, C. Appl. Catal., A 2001, 208, 193-201. doi:10.1016/S0926-860X(00)00713-4

44. Hinnemann, B.; Nørskov, J. K. Top. Catal. 2006, 37, 55-60. doi:10.1007/s11244-006-0002-0

45. Foster, A. I.; James, P. G.; McCarroll, J. J.; Tennison, S. R. Process for the synthesis of ammonia using catalysts supported on graphite containing carbon. U. S. Patent 4,163,775, 1979.

46. Kowalczyk, Z.; Jodzis, S.; Raróg, W.; Zieliński, J.; Pielaszek, J.; Presz, A. Appl. Catal., A 1999, 184, 95-102. doi:10.1016/S0926-860X(99)00090-3

47. Kowalczyk, Z.; Krukowski, M.; Raróg-Pilecka, W.; Szmigiel, D.; Zielinski, J. Appl. Catal., A 2003, 248, 67-73. doi:10.1016/S0926-860X(03)00150-9

48. Hansen, T. W.; Hansen, P. L.; Dahl, S.; Jacobsen, C. J. H. Catal. Lett. 2002, 84, 7-12. doi:10.1023/A:1021028718491

49. Raróg-Pilecka, W.; Miśkiewicz, E.; Kępiński, L.; Kaszkur, Z.; Kielar, K.; Kowalczyk, Z. J. Catal. 2007, 249, 24-33. doi:10.1016/j.jcat.2007.03.023

50. Yang, Z.; Guo, W.; Lin, J.; Liao, D. Chin. J. Catal. 2006, 27, 378-380. doi:10.1016/S1872-2067(06)60022-3

51. Vidick, D.; Leonard, A. F.; Poleunis, C.; Delcorte, A.; Devillers, M.; Hermans, S. Catal. Today 2014, 235, 112-126. doi:10.1016/j.cattod.2014.03.017

52. Mingos, D. M. P.; Watson, M. J. Adv. Inorg. Chem. 1992, 39, 327-399. doi:10.1016/S0898-8838(08)60262-7

53. Willocq, C.; Vidick, D.; Tinant, B.; Delcorte, A.; Bertrand, P.; Devillers, M.; Hermans, S. Eur. J. Inorg. Chem. 2011, 4721-4729. doi:10.1002/ejic.201100384

54. Moggi, P.; Albanesi, G.; Predieri, G.; Spoto, G. Appl. Catal., A 1995, 123, 145-159. doi:10.1016/0926-860X(94)00239-8

55. Aika, K.-i.; Takano, T.; Murata, S. J. Catal. 1992, 136, 126-140. doi:10.1016/0021-9517(92)90112-U 
56. Guo, S.; Pan, X.; Gao, H.; Yang, Z.; Zhao, J.; Bao, X. Chem. - Eur. J. 2010, 16, 5379-5384. doi:10.1002/chem.200902371

57. Li, Z. L.; Liang, C. H.; Feng, Z. C.; Feng, Z. C.; Ying, P. L.; Wang, D. Z.; Li, C. J. Mol. Catal. A: Chem. 2004, 211, 103-109. doi:10.1016/j.molcata.2003.09.028

58. Raróg-Pilecka, W.; Miśkiewicz, E.; Szmigiel, D.; Kowalczyk, Z. J. Catal. 2005, 231, 11-19. doi:10.1016/j.jcat.2004.12.005

59. Liang, C.; Li, Z.; Qiu, J.; Li, C. J. Catal. 2002, 211, 278-282. doi:10.1016/S0021-9517(02)93724-3

\section{License and Terms}

This is an Open Access article under the terms of the Creative Commons Attribution License

(http://creativecommons.org/licenses/by/2.0), which permits unrestricted use, distribution, and reproduction in any medium, provided the original work is properly cited.

The license is subject to the Beilstein Journal of

Nanotechnology terms and conditions:

(http://www.beilstein-journals.org/bjnano)

The definitive version of this article is the electronic one which can be found at: doi:10.3762/bjnano.6.133 